\title{
Pengembangan Media Pembelajaran Sistem Pencernaan Manusia Berorientasi Teori Belajar Ausubel Kelas V Sekolah Dasar
}

\author{
Pt. Wahyu Bagiana Putra ${ }^{1 *}$, I. Gst. Agung Ayu Wulandari² \\ 12 Universitas Pendidikan Ganesha, Singaraja, Indonesia \\ *e-mail: putuwahyubagianaputra23@Undiksha.ac.id
}

\begin{abstract}
Abstrak
Kurangnya penggunaan media pembelajaran yang dapat digunakan dalam pembelajaran dengan sistem dalam jaringan pada muatan IPA materi sistem pencernaan manusia pada kelas $\mathrm{V}$ menjadi salah satu alasan dari dilaksanakannya penelitian pengembangan ini. Penelitian ini dilaksanakan dengan tujuan untuk untuk merancang media pembelajaran berupa aplikasi belajar untuk materi IPA mengenai sistem pencernaan pada manusia, kelas V SD dengan berorientasi pada teori belajar Ausubel, serta untuk mengetahui bagaimana validitas media pembelajaran yang dikembangkan berdasarkan hasil validasi oleh pakar ahli dan uji coba produk pada siswa. Pada penelitian ini, data dikumpulkan menggunakan metode non-tes dengan instrumen berupa lembar kuesioner dengan menggunakan skala likert. Penelitian ini menerapkan model pengembangan ADDIE yang terdiri atas tahap Analyse, Design, Development, Implementation, dan Evaluation. Hasil validasi produk oleh ahli isi dengan total persentase $91,66 \%$ dengan kualifikasi sangat baik. Hasil validasi dari ahli media pembelajaran dengan total persentase $97,50 \%$ dengan kategori sangat baik. Hasil validasi ahli desain pembelajaran dengan total persentase $90,00 \%$ dengan kategori sangat baik. Hasil uji coba perorangan dengan persentase $90,15 \%$ dengan kategori sangat baik dan hasil uji coba kelompok kecil dengan total persentase $84,85 \%$ dengan kategori baik. Berdasarkan hasil validasi pakar ahli dan uji coba produk pada siswa, media pembelajaran sistem pencernaan berorientasi teori belajar Ausubel dinyatakan valid dan layak digunakan sebagai media pembelajaran untuk SD pada muatan IPA materi sistem pencernan manusia kelas V SD.
\end{abstract}

Kata kunci: media pembelajaran, ipa, sistem pencernaan manusia

\begin{abstract}
This research is a type of development research carried out with the aim to design learning media in the form of learning applications for natural science material regarding the digestive system in humans, in $V$ grade elementary school students oriented to Ausubel learning theory, to find out how quality and the feasibility of learning media developed based on the results of validation by experts and product trials on students. This research was conducted because of the lack of use of instructional media that can be used in learning with online systems. In this study, data were collected using the non-test method with the instrument used in the form of a questionnaire sheet with a Linkert scale. This study applies the ADDIE development model consisting of the stages, analyze, design, development, implementation, and evaluation. The results of product validation by content experts with a total percentage of $96.42 \%$ with very good qualifications. The validation results from the instructional media experts with a total percentage of $97.95 \%$ with very good categories. The results of the validation of the learning design expert with a total percentage of $90.00 \%$ in the very good category. The results of individual trials with a percentage of $90.15 \%$ in the very good category and the results of small group trials with a total percentage of $84.85 \%$ in the good category. Based on the results of expert validation and product trials on students of learning media for the digestive system application-oriented to Ausubel learning theory, it is feasible to be used as a learning medium on the science content of human digestion system material for $V$ grade elementary school students.
\end{abstract}

Keywords: learning media, natural scienc, human digestive system

\footnotetext{
*Corresponding author.

Received 30 Januari 2021; Accepted 1 Maret 2021; Available online 8 April 2021 (c) 2021 MI All Rights Reserved
} 


\section{Pendahuluan}

Pendidikan dipandang sebagai suatu usaha sadar untuk mencapai perbaikan pada segala bidang dan aspek kehidupan yang disebut juga sebagai proses memanusiakan manusia yang berlangsung pada lingkungan masyarakat secara turun temurun dari satu generasi ke generasi berikutnya (Dantes, 2014; Rahmi et al., 2019). Sebagai mahluk hidup, manusia akan selalu mengalami perkembangan dalam hidupnya yang selalu berusaha untuk meningkatkan kehidupannya menjadi lebih baik lagi, dan selama itu pula pendidikan akan terus berkembang dari generasi ke generasi berikutnya (Sadulloh, 2004). Melalui pendidikan taraf hidup seseorang dapat berubah menjadi lebih baik (Suprianingsih \& Wulandari 2020). Pendidikan ini erat kaitanya dengan kegiatan pembelajaran yang merupakan kegiatan interaksi antara guru dan siswa yang terjadi secara dua arah untuk mencapai tujuan pembelajaran yang sudah ditetapkan sebelumnya (Tabany, 2014). Pemberian pembelajaran pada sekolah dasar dengan kurikulum 2013 menggunakan pembelajaran tematik terpadu dengan menerapkan pendekatan ilmiah, artinya siswa dibelajarkan melalui proses penemuan/penelitian dari siswa itu sendiri (Suadnyana et al., 2017). Kegiatan pembelajaran akan membantu peserta didik dalam mengembangkan sekaligus mengubah perilaku siswa kearah yang lebih baik (Yektyastuti, \& Ikhsan, 2016). Pembelajaran yang efektif adalah pembelajaran yang berlangsung aktif dan mampu menjadikan siswa semangat dalam pembelajaran. Sejalan dengan itu, pembelajaran yang mampu menjadikan siswa semangat dan mampu meningkatkan motivasinya dalam belajar merupakan indikator dari kualitas pendidikan yang dilaksanakan. Motivasi belajar siswa merupakan indikator keberhasilan pelaksanaan pembelajaran yang efektif (Rasyid, et al., 2016). Pembelajaran yang efektif harus mampu menjadikan siswa termotivasi dalam pembelajaran. Teknologi juga memiliki andil yang sangat besar dalam kehidupan sehari-hari (Astuti, et al., 2017) yang dapat dimanfaatkan sebagai media dalam pembelajaran akan dapat meningkatkan efektifitas pembelajaran (Jayanta, 2018).

Muatan materi pada pembelajaran di sekolah dasar yang yang penting untuk dipahami siswa dalah materi pada muatan IPA sistem pencernaan manusia. Pemberian pembelajaran IPA materi sistem pencernaan manusia penting untuk dipahami oleh siswa (Permana \& Nourmavita, 2017), karena dengan belajar IPA siswa akan mampu belajar tentang lingkunganya dan dirinya sendiri (Hermono, Fajar \& Hakim, 2012). Sistem pencernan manusia merupakan suatu proses bagaimana tubuh mengolah dan memproses makanan yang masuk kedalam tubuh yang melibatkan organ-organ pencernaan (Susanto, 2013). Materi IPA mengenai sistem pencernaan manusia merupakan materi yang sulit dipahami siswa tanpa adanya penjelasan oleh guru. Pendapat ini dipertegas oleh (Saputro, \& Saputra, 2014; Mauludin, et al., 2017) yang menyatakan bahwa materi sistem pencernaan manusia ini merupakan materi yang sulit bagi siswa SD karena organ yang terlibat dalam proses pencernaan tidak dapat dilihat secara langsung dengan mata sehingga memerlukan media pembelajaran yang dapat digunakan untuk membantu siswa dalam mempelajari materi sistem pencernaan manusia dengan lebih baik.

Namun kenyataanya pada kelas V SD Negeri 3 Celuk Sukawati, dikarenakan pandemi covid-19 menjadikan kegiatan pembelajaran tidak dapat dilaksanakan secara konvensional mengharuskan siswa untuk belajar secara mandiri dari rumah masing-masing dengan sistem dalam jaringan "Daring". Kegiatan pembelajaran yang seharusnya mampu menjadikan siswa termotivasi dalam pembelajaran nyatanya tidak dapat dilaksanakan dengan optimal serta memiliki beberapa permasalahan. Materi sistem pencernaan manusia yang merupakan materi yang bersifat abstrak diketahui masih kurang penggunaan media pembelajaran yang mengaitkan pemahaman awal siswa dengan materi yang akan dibelajarkan. Pembelajaran hanya dilakukan melalui sarana WhatsApp Group dan Google Calssroom untuk mengumpulkan tugas yang menjadikan kegiatan pembelajaran didalamnya tidak terjadi komunikasi 2 arah antara guru dengan siswa, yang menjadikan siswa kurang aktif dalam pembelajaran, sehingga pembelajaran tidak berjalan dengan efektif. Hal ini sejalan dengan pernyataan (Udayani, et al., (2015), yang menyatakan bahwa pembelajaran 
yang kurang melibatkan siswa untuk aktif dan penyajian penyampaian materi yang kurang menarik akan menjadikan siswa bosan dalam belajar. Selain itu, diketahui pula bahwa dalam pembelajaran siswa sulit untuk mencari tambahan materi pembelajaran secara mandiri dikarenakan dalam pembelajaran daring yang berlangsung, guru tidak dapat melakukan pendampingan kepada siswa secara intensif terhadap materi yang dibelajarkan.

Berdasarkan permasalahan tersebut solusi yang dapat dilakukan yakni dengan mengemas pembelajaran dengan menggunakan media pembelajaran multimedia berupa aplikasi dengan menerapkan teori belajar Ausubel yang interaktif yang mampu meningkatkan minat belajar siswa dengan berorientasi pada teori belajar Ausubel dalam pengembanganya. Media multimedia merupakan media yang mengintegrasikan semua bentuk media meliputi teks, gambar, audio, video, interaktivitas dalam satu bentuk media yang diprogramkan dengan berlandaskan pada teori dan pembelajaran yang digunakan (Warsita, 2008). Hal ini sejalan dengan pendapat (Rosandi et al., 2016) yang menyatakan bahwa penggunaan media pembelajaran multimedia mampu menjadikan proses pembelajaran menjadi lebih bermakna dan menyenangkan bagi siswa. Dengan mengemas pembelajaran menggunakan media pembelajaran sebagai penyalur informasi dari pengirim pesan ke penerima pesan dalam pembelajaran (Juannita, \& Adhi 2017), maka perhatian siswa terhadap materi yang disampaikan akan meningkat (Ahmadi, et al., 2017; Muhson, 2010). Pembelajaran yang menarik menjadikan siswa lebih senang dan mudah memahami materi yang diberikan (Kartini \& Putra, 2020). Pemberian pembelajaran di SD dilaksanakan dengan mengajak siswa mengaitkan materi pelajaran pada hal-hal yang bersifat nyata dalam kehidupan sehari-hari siswa akan sangat cocok diberikan sesuai dengan penerapan teori belajar yang diperkenalkan oleh David $\mathrm{P}$ Ausubel, yang menyatakan bahwa untuk membantu siswa memahami suatu materi yang dibelajarkan, diperlukan pengaitan antara materi yang akan dibelajarkan dengan konsep yang telah dimiliki siswa sebelumnya (Gazali, 2016; Saputra, 2016). Dengan menerapkan kebermaknaan dalam pembelajaran, siswa akan mampu mencari hubungan antara konsep baru dengan pengetahuan siswa sebelumnya, sehingga pemahaman siswa terbangun lebih baik (Kinasih, et al., 2020). Dengan pemberian pembelajaran yang memiliki kerbermaknaan, akan membantu siswa dalam memahami materi dengan membuat makna atas pengalamanya yang bersifat nyata yang diaitkan dengan materi yang akan dipelajari (Syahdiani, 2015). Sehingga pembelajaran dengan sistem daring yang dilaksanakan dapat berjalan dengan lebih efektif menarik serta mampu meningkatkan motivasi siswa dalam pembelajaran.

Dengan mengembangkan suatu media pembelajaran berupa aplikasi dengan berorientasi pada teori belajar Ausubel, akan mampu menjadikan pembelajaran lebih efektif dan siswa lebih mudah memahami materi yang dibelajarkan. Media pembelajaran berupa aplikasi ini dikembangkan dengan menyesuaikan KD dan indikator materi pada kelas $\mathrm{V}$ yang dapat digunakan pada smartphone dengan sistem operasi android dengan maupun tanpa adanya data internet, sehingga siswa dapat belajar kapanpun, dimanapun dan tidak kesulitan mencari tambahan materi sendiri dan dapat melakukan interaksi dengan media yang dikembangkan. Hal ini sangat sesuai bila diterapkan dalam pembelajaran IPA yang bersifat abstrak dan memerlukan media interaktif sebagai sarana yang mampu menjadikan materi IPA sistem pencernaan manusia yang tidak dapat dilihat secara langsung menjadi mudah untuk dipahami. Sehingga siswa dapat melakukan interaksi dengan materi yang dipelajari melalui media yang digunakan (Suartama, 2010).

Penelitian ini didukung oleh penelitian sebelumnya oleh (Sulistyanto \& Nugroho, 2015) yang mengembangkan media pembelajaran aplikasi sistem organ pada manusia yang menghasilkan media pembelajaran yang mampu meningkatkan pemahaman siswa terhadap materi dan membantu guru dalam menyampaikan materi kepada siswa serta penelitian oleh (Tamara et al., 2019) yang mengembangkan media pembelajaran aplikasi interaktif sistem pencernaan manusia untuk SD yang menghasilkan media pembelajaran multimedia berupa aplikasi yang mampu membantu meningkatkan pemahaman siswa terhadap materi sistem pencernaan manusia yang mudah dimengerti dan dipahami siswa.

Berdasarkan permasalahan tersebut penelitian ini bertujuan untuk mengembangkan 
suatu media pembelajaran berupa aplikasi sistem pencernaan manusia dengan berorientasi teori belajar Ausubel dan untu mengatahui hasil validasi media yang dikembangkan berdasarkan review pakar ahli dan siswa. Penelitian ini menjadi penting dilaksanakan karena materi IPA akan lebih mudah dipahami siswa bila siswa telah memiliki pemahaman sebelumnya.

\section{Metode}

Penelitian ini dilakukan untuk mengembangakan suatu media pembelajaran berupa aplikasi yang diberi nama SiCeria dengan berorientasi pada teori belajar Ausubel yang dilaksanakan pada kelas V SD Negeri 3 Celuk Sukawati Gianyar. Penelitian ini merupakan penelitian dengan jenis pengembangan yang menggunakan model pengembangan ADDIE yang terdiri atas lima tahapan meliputi tahap Analysis (analisis), Design (desain), Development (pengembangan), Implementation (implementasi) dan Evaluationt (evaluasi) (Tegeh, et al., 2014).

Pada tahap analysis (analisis), dilaksanakan analisis kondisi awal, analisis kebutuhan di lapangan serta analisis kompetensi dasar dan indikator materi. Kemudian pada tahap design (desain) dilakukan kegiatan merancang media yang dikembangkan meliputi pengumpulan data, menyususn flowchart dan menyusun storyboard. Pengumpulan data dilakukan untuk mengumpulkan segala hal yang akan materi, gambar, audio, video dan software yang digunakan dalam mengembangkan media yang dikembangkan. Flowchart merupakan bagan alur yang menunjukan langkah kerja program (Warsita, 2008). Selanjutnya menyusun storyboard yang merupakan sketsa gambaran tampilan produk yang dikembangkan (Permana, \& Nourmavita, 2017). Pada tahap development (pengembangan)

dilakukan proses pengembangan media aplikasi SiCeria berorientasi teori belajar Ausubel sesuai dengan rancangan sebelumnya yang meliputi pembuatan interface menggunakan powerpoint atau tampilan aplikasi menggunakan powerpoint, menambahakan isi materi pada interface menggunakan powerpoint, menambahkan interaktivitas menggunakan powerpoint, menambahkan quis interaktif menggunakan iSpring Suite9, mendesain logo aplikasi menggunakan Adobe Photoshop CS3, mengubah format data menjadi HTML menggunakan iSpring Suite9, mengubah HTML menjadi aplikasi (.apk) menggunakan Website 2 Apkbuilder Pro v4.4, instalisasi aplikasi pada smartphone, menyusun angket, dan melaksanakan validasi produk dengan pakar ahli dan siswa sebagai subjek uji coba produk. Pada tahap implementasi

dikarenakan penelitian ini dilaksanakan pada masa pandemi covid-19, sehingga untuk tahap penerapan media yang dikembangkan pada pembelajaran secara langsung tidak dapat dilaksanakan dan dilanjutkan dengan tahap evaluasi yang dilaksanakan secara formatif untuk mengetahui hasil validasi produk yang dikembangkan.

Pakar ahli yang dilibatkan dalam penelitian ini adalah 1 orang ahli isi mata pelajaran, 1 orang ahli media pembelajaran serta 1 orang ahli desain pembelajaran. Subjek uji coba yang digunakan dalam penelitian ini adalah 9 orang siswa kelas $V$ SD sebagai subjek uji coba perorangan yang melaibatkan 3 orang siswa serta subjek uji coba kelompok kecil yang melibatkan 6 orang siswa. Data yang dikumpulkan dalam penelitian ini untuk mengetahui kualifikasi media yang dikembangkan, menggunakan metode non tes yakni kuesioner dengan istrumen pengumpulan data yang digunakan berupa lembar kuesioner.

Pada penelitian ini jenis data yang digunakan adalah data kuantitatif yang didapatkan dari hasil jawaban pada lembar kuesioner yang diberikan kepada pakar ahli dan siswa sebagai subjek uji coba produk yang dijabarkan dengan skala likert dengan skala 4 yang terdiri atas sangat setuju (SS), setuju (S), tidak setuju (TS), sangat tidak setuju (STS) yang kemudian dikonversi menggunakan skala likert 4 sebagai berikut $S S=4 ; S=3$; TS $=2$; $S T S$ $=1$ untuk dicari persentasenya.

Kemudian data berupa skor yang didapatkan dianalisis menggunakan teknik analisis deskriptif kuantitatif dengan menyususun data dengan sistematis berupa angka maupun 
persentase untuk menarik suatu kesimpulan (Agung, 2014), yang kemudian dikonversikan dengan tabel pencapaian media untuk mengetahui validasi media yang dikembangkan apakah sangat baik, baik, cukup, kurang atau sangat kurang. Selanjutnya komentar, saran, tanggapan dari masing-masing pakar ahli dan siswa sebagai subjek uji coba produk digunakan sebagai acuan dalam melaksankan perbaikan pada media yang dikembngkan.

$$
\mathrm{P}=\frac{\Sigma R}{N} \times 100 \%
$$

$$
\begin{aligned}
& \text { Keterangan : } \\
& P=\text { Presentase nilai yang diperoleh. } \\
& \begin{array}{l}
\sum_{N} \mathrm{R}=\text { jumlah jawaban yang terpilih } \\
\text { Jumlah skor maksimal atau ideal }
\end{array}
\end{aligned}
$$

\section{Hasil dan Pembahasan}

\section{Hasil Penelitian}

Produk yang dihasilkan dalam penelitian pengembangan ini adalah media pembelajaran berupa aplikasi yang dapat digunakan pada smarthphone dengan sistem operasi android yang diberi nama SiCeria dengan berorientasi pada teori belajar Ausubel. Pada tahap analisis, berdasarkan analisis kondisi awal, diketahui bahwa kegiatan pembelajaran dengan sistem daring di kelas V SD Negeri 3 Celuk Sukawati Gianyar masih kurang adanya interaksi guru dengan siswa dan penggunaan media pembelajaran yang sesuai digunakan dalam pembelajaran dengan sistem daring, dalam kegiatan pembelajaran siswa menyatakan bahwa pembelajaran membosankan, siswa merasa senang belajar jika dalam pembelajaran menggunakan media pembelajaran yang menarik, yang terdapat gambar, audio, teks, interaktivitas yang disesuaikan dengan materi yang dibelajarkan. Berdasarkan hasil analisis kebutuhan dan analisis KD dan indikator diketahui bahwa muatan IPA materi sistem pencernaan manusia pada tema 3 membutuhkan media yang inovatif dan interaktif yang dapat digunakan dalam pembelajaran dengan sistem daring untuk memudahkan siswa memahami materi yang dibelajarkan. Hal ini sejalan dengan pendapat (Sari, et al., 2013) yang menyatakan bahwa materi IPA dalam kegiatan pembelajaran memerlukan media pembelajaran yang dapat digunakan untuk menunjukan secara kongkret suatu materi yang sulit dipelajari tanpa dilihat secara langsung.

Pada tahap pengembangan dilaksanakan pembuatan media serta validasi media oleh pakar ahli dan subjek uji coba yang meliputi uji perorangan dan kelompok kecil. Pada penelitian ini untuk tahap implementasi dengan menerapkan media yang dikembangkan secara langsung dalam pembelajaran tidak dapat dilaksanakan dikarenakan situasi pandemi yang tidak memungkinkan. Tahapan evaluasi dilaksanakan pada tiap tahapan yang sebatas pada evaluasi formatif Adapun tampilan media yang dikembangkan sebagai berikut:

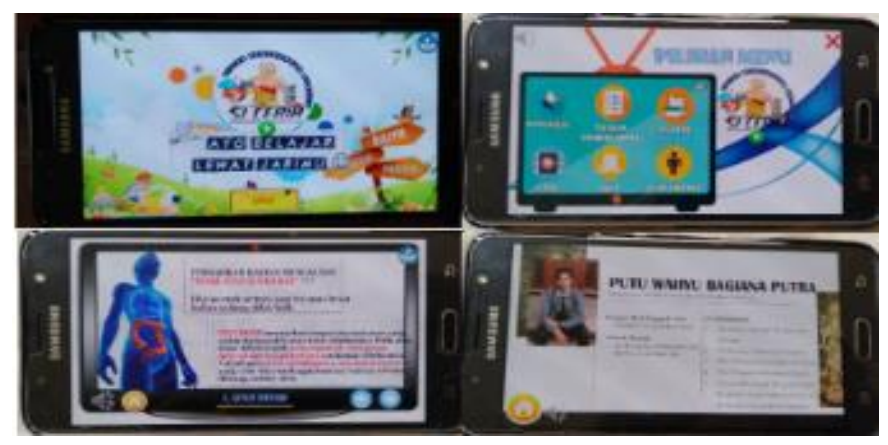

Gambar 3. Tampilan layar dan isi aplikasi

Berikut adalah hasil validasi ahli dan siswa berdasarkan jawaban pada instrumen 
Tabel 1. Hasil validasi produk

\begin{tabular}{lc}
\hline \multicolumn{1}{c}{ Subjek Uji Coba } & Hasil Validasi (\%) \\
\hline Ahli Isi Mata Pelajaran & 91,66 \\
Ahli Media Pembelajaran & 97,50 \\
Ahli Desain Pembelajaran & 90,00 \\
Uji Coba Perorangan & 90,15 \\
Uji Coba Kelompok Kecil & 84,85 \\
\hline
\end{tabular}

Berdasarkan saran dan masukan yang diberikan oleh pakar ahli serta siswa sebagai subjek uji coba produk untuk menjadikan media yang dikembangkan layak digunakan berikut dipaparkan revisi dari pakar ahli dan siswa:

Tabel 2. Revisi Produk Ahli Isi

\begin{tabular}{llll}
\hline No & \multicolumn{1}{c}{ Komentar } & Revisi \\
\hline 1. & $\begin{array}{l}\text { Materi pada Media layak digunakan tanpa } \\
\text { revisi }\end{array}$ & - & \\
\hline
\end{tabular}

Tabel 3. Revisi Produk Ahli media pembelajaran

\begin{tabular}{lll}
\hline No & \multicolumn{1}{c}{ Komentar } & \multicolumn{1}{c}{ Revisi } \\
\hline 1. & Penggunaan huruf pada tampilan materi & Merubah font tulisan pada \\
& agar menggunakan font yang standar. & $\begin{array}{l}\text { aplikasi agar menggunakan font } \\
\text { yang standar agar mudah } \\
\text { dibaca. }\end{array}$ \\
& & \\
\hline
\end{tabular}

Tabel 4. Revisi Produk Ahli media pembelajaran

\begin{tabular}{lll}
\hline No & \multicolumn{1}{c}{ Komentar } & \multicolumn{1}{c}{ Revisi } \\
\hline 1. & Rumusan tujuan pembelajaran disusun & Menyesuaikan tujuan \\
& lebih jelas. & pembelajaran dengan kegiatan \\
& $\begin{array}{l}\text { Sesuaikan kegiatan pembelajaran } \\
\text { dengan dengan tujuan pembelajaran } \\
\text { yang harus dicapai siswa. }\end{array}$ & $\begin{array}{l}\text { yang dilakukan siswa untuk } \\
\text { mencapai tujuan pembelajaran } \\
\text { tersebut }\end{array}$ \\
\hline
\end{tabular}

\section{Pembahasan}

Pada penelitian ini, dikembangkannya media pembelajaran sistem pencernaan manusia berorientasi teori belajar Ausubel ini dikarenakan materi IPA sistem pencernaan manusia ini merupakan materi yang sulit dipahami siswa tanpa adanya penjelasan langsung oleh guru karena materi yang tidak dapat dilihat secara langsung oleh mata siswa, namun kenyataanya di dalam pembelajaran yang berlangsung dengan sistem daring ini sangat minim adanya interaksi antara guru dengan siswa dan kurang penggunaan media pembalajaran yang inovatif sehingga pembelajaran cenderung monoton dan membosankan bagi siswa. Media yang digunakan guru masih sangat minim dengan pengaitan pengetahuan awal siswa dengan materi yang dibelajarkan. Hal ini dikarenakan adanya keluahan dan permintaan dari orang tua siswa yang kesulitan jika menggunakan sarana belajar yang menggunakan kuota internet yang besar, sehingga pembelajaran yang dilaksanakan hanya mengguanakan WAG dan Classroom saja. Oleh karena itu dikembangkan suatu media pembelajaran aplikasi yang lengap berisi materi, video pembelajaran, audio, interaktivitas dan quis yang dikemas menarik yang mampu digunakan siswa untuk mempelajari materi sistem pencernaan manusia secara mandiri kapanpun dan dimanapun bahkan dengan tanpa 
data internet sehingga siswa dapat berinteraksi secara langsung melalui aplikasi yang dikembangkan. Hal ini sejalan dengan pendapat (Arywiantari, Dadek, 2015; Fanny \& Suardiman, 2013) yang menyatakan bahwa media multimedia mampu menjadikan siswa aktif dalam pembelajaran dan meningkatkan gairah siswa dalam mempelajari materi yang dibelajarkan.

Media yang dikembangkan ini berdasarkan hasil validasi produk oleh ahli isi mata pelajaran, media yang dikembangkan dinyatakan layak untuk digunakan dalam pembelajaran dengan kualifikasi sangat baik dilihat dari kesesuaian antara materi yang ditampilkan pada media dngan materi sistem pencernaan pada muatan IPA tema 3 kelas V, kesesuaian dengan kompetensi dasar, indikator serta tujuan pembelajaran yang harus dicapai siswa melalui media pembelajaran yang dikembangkan, divalidasi dari sisi kemenarikan penyajian materi pada aplikasi. Hal ini sejalan dengan pendapat (Nurseto, 2011) yang menyatakan bahwa materi pada media harus sesuai dengan isi mata pelajaran dan memuat capaian yang harus dikuasai siswa. Media pembelajaran aplikasi SiCeria berorientasi teori belajar Ausubel ini dikembangkan untuk membantu siswa dalam mempelajari materi IPA sistem pencernaan manusia yang sulit dipahami siswa tanpa adanya bimbingan dan interaksi dengan guru dalam kegiatan pembelajaran daring yang tidak dapat dilihat secara langsung oleh mata. Hal ini sejalan dengan pendapat (Sari, Puspita Surya, 2013) yang menyatakan bahwa pembelajaran IPA pada hakikatnya mengajak siswa untuk mampu membangun yang berkaitan dengan hal-hal yang dekat dengan siswa secara kongkret yang sulit untuk dipelajari yang tidak dapat dilihat secara langsung, sehingga pembelajaran IPA dengan menggunakan media pembelajaran yang sesuai akan sangat tepat digunakan dalam pembelajaran.

Hasil validasi produk oleh ahli media pembelajaran, media yang dikembangkan dinyatakan layak untuk digunakan dalam pembelajaran dengan dengan kualifikasi sangat baik, yang ditinjau dari segi kemenarikan tampilan aplikasi, serta kesesuaian komponen yang terdapat dalam aplikasi yang dikembangkan dengan menggunakan font hurup yang mudah dibaca siswa dengan jenis sans serif yakni Times New Roman lebih mudah dibaca (Sudatha \& Tegeh, 2009). Siswa lebih menyukai bentuk hurup yang komunikatif dengan warna yang menarik (Maesaroh, 2015). Siswa lebih menyukai font yang bentuknya fleksibel serta dinamis sesuai karakter anak (Nusantara, \& Irawan, 2015). Sejalan dengan itu (Fitri, 2017) meyatakan bahwa siswa sekolah dasar pada pada dasarnya cenderung akan tertarik pada permainan dan sesatu yang penuh dengan warna yang menarik. Dengan penggunaan media yang menarik dan interaktif, siswa diharapkan akan lebih memahami materi pembelajaran yang dibelajarkan. Hal ini sejalan dengan dengan pendapat (Tamara et al., 2019) yang menyatakan bahwa pengggunaan media yang menggabungkan unsur multimedia didalamnya mampu menjadikan pembelajaran lebih menarik, pembelajaran menjadi lebih efektif karena siswa aktif berinteraksi dengan media yang digunakan (Nurseto, 2011), sehingga pembelajaran yang awalnya minim terjadi interaksi antara guru dengan siswa dan dirasa membosankan menjadi efektif dan menarik bagi siswa. Berdasarkan hasil validasi ahli desain pembelajaran, media yang dikembangkan dinyatakan layak untuk diterapkan dalam proses pembelajaran sebagai sarana penunjang pembelajaran dengan kualifikasi sangat baik ditinjau dari kejelasan tujuan umum meliputi kesesuaian KD, indikator dan tujuan pembelajaran pada RPP, strategi pembelajaran dan kesesuaian evaluasi pembelajaran. kualitas pembelajaran akan ditentukan dari pelaksanaan pembelajaran yang mampu memotivasi siswa dalam pembelajaran (Nida, 2020).

Hasil uji coba produk secara perorangan dengan melibatkan 3 orang siswa dengan kualifikasi sangat baik, dan hasil uji coba produk secara kelompok kecil dengan kualifikasi baik. Media pembelajaran yang dikembangkan dapat digunakan sebagai media pembelajaran interaktif yang dapat digunakan dapat kegiatan pembelajaran untuk materi sistem pencernaan manusia secara daring. Sehingga siswa dapat melakukan interaksi dengan media yang dikembangkan walaupun tanpa adanya data internet yang dapat digunakan untuk belajar kapanpun dan dimanapun oleh siswa, sehingga pemahaman materi sistem pencernaan manusia yang sulit dipahami siswa tanpa adanya bimbingan langsung 
oleh guru dapat terlaksana dengan lebih optimal dan pembelajaran dapat berjalan dengan lebih efektif. Hal ini sesuai dengan hasil beberapa penelitian sebelumnya yang relevan dengan penelitian ini diantaranya penelitian dari (Setiyaningrum, 2013) yang mengembangkan media pembelajaran multimedia interaktif IPA kelas VIII mengenai sistem pencernaan manusia yang menyatakan bahwa siswa lebih memahami materi yang diberikan dengan menggunakan media yang dikembangkan, dan penelitian dari (Yuniasih, et al., 2018) yang mengembangkan media pembelajaran interaktif materi sistem pencernaan pada kelas $\checkmark$ SD yang menghasilkan media pembelajaran dengan kualifikasi sangat baik dan layak untuk diterapkan dalam pembelajaran. hasil penelitian dari (Sulistyanto \& Nugroho, 2015) yang mengembangkan media aplikasi pembelajaran sistem organ berbasis web dengan hasil bahwa media yang dikembnagkan mampu meningkatkan pemahaman siswa terhadap materi sistem organ menjadi lebih baik, serta penelitian oleh (Prasetyo, 2017) dengan penelitian yang mengembangkan media pembelajaran IPA berbasis android untuk SD/MI dengan hasil validasi media sangat baik untuk diterapkan dalam kegiatan pembelajaran.

\section{Simpulan}

Berdasarkan hasil analisis data dan pembahasan, maka disimpulkan sebagai berikut. Rancang bangun media pembelajaran aplikasi SiCeria berorientasi teroi belajar ausubel, mengikuti tahapan pada model pengembangan yang digunakan yaitu model pengembangan ADDIE yang meliputi Analysis (Analisis), tahap Design (Desain), tahap Development (Pengembangan) dan tahap Evaluation (Evaluasi) yang dilaksanakan secara formatif, dan untuk tahap implementasi produk tidak dapat dilaksanakan dikarenakan situasi pandemi covid-19. Media pembelajaran SiCeria yang dikembangkan dinyatakan Valid berdasarkan hasil validasi ahli isi mata pelajaran dengan kualifikasi sangat baik dan dinyatakan layak digunakan, hasil validasi alhi media pembelajaran dengan kualifikasi sangat baik dan dinyatakan layak utuk digunakan, hasil validasi ahli desain pembelajaran dengan kualifikasi sangat baik dan dinyatakan layak untuk digunakan dalam pembelajaran, hasil uji coba perorangan dengan kategori sangat baik dan uji coba kelompok kecil dengan dengan kualifikasi baik.

\section{Daftar Pustaka}

Agung, A. A. G. (2014). Metodologi Penelitian Pendidikan. Aditya Media Publishing.

Ahmadi, Farid, D. (2017). Dasar, Pengembangan Media Edukasi "Multimedia Indonesian Culture" (Mic) Sebagai Penguatan Pendidikan Karakter Siswa Sekolah. Jurnal Penelitian Pendidikan, 34(2), 127-136. Http:// Lib. Unnes. Ac. Id/37234/

Al-Tabany, B. (2014). Mendesain Model Pembelajaran Inovatif, Progresif, Dan Kontekstual. Kencana.

Arywiantari, Dadek, D. (2015). Pengembangan Multimedia Interaktif Model 4d Pada Pembelajaran Ipa Di Smp Negeri 3 Singaraja. E-Journal Edutech Universitas Pendidikan Ganesha, 3(1), 1-11.Https:// Ejournal. Undiksha. Ac. Id /Index. Php/ Jeu/ Article/ View/5611

Astuti, Irnin Agustina Dwi, Dkk. (2017). Pengembangan Media Pembelajaran Mobile Learning Berbasis Android Pada Materi Sifat Koligatif Larutan. Jrpk: Jurnal Riset Pendidikan Kimia, 7(2), 160-167. Https://Doi.Org/10.21009/Jrpk.072.10

Dantes, N. (2014). Landasan Pendidikan Tinjauan Dari Dimensi Makropedagogis. Graha IImu.

Fanny, A. M., \& Suardiman, S. P. (2013). Pengembangan Multimedia Interaktif Untuk Mata Pelajaran IImu Pengetahuan Sosial (Ips) Sekolah Dasar Kelas V. Jurnal Prima Edukasia, 1(1), 1. Https://Doi.Org/10.21831/Jpe.V1i1.2311 
Fitri, Y. (2017). Pengembangan Media Pembelajaran Berbasis Adobe Flash Cs3 Professional Dalam Pembelajaran Ipa Berbasis Integrasi Islam-Sains Di Sd/Mi Kelas 5. Trihayu: Jurnal Pendidikan Ke-Sd-An, 3(3), 129-138. Http:// Jurnal. Ustjogja. Ac. Id/ Index. Php/ Trihayu/Article/View/1874/1043

Gazali, R. Y. (2016). Pembelajaran Matematika Yang Bermakna. Math Didactic, 2(3), 181190. Https://Doi.Org/10.33654/Math.V2i3.47

Hermono, Fajar, \&, \& Hakim, F. N. (2012). Dperancangan Media Pembelajaran Berbasis Multimedia (Studi Kasus Mata Pelajaran Ipa Bahasan Gerak Benda Kelas lii Sdn Demplerejo). Journal Speed - Sentra Penelitian Engineering Dan Edukasi, 4(1), 4249. Http://Www.ljns.Org/Journal/Index.Php/Speed/Article/View/1162

Jayanta, L. (2018). Dasar- Dasar Tik. Fakultas IImu Pendidikan Universitas Pendidikan Ganesha.

Juannita, \& A. B. P. (2017). Pengembangan Media Pembelajaran Sistem Pencernaan Manusia Untuk Kelas $8 \mathrm{Smp}$ Dengan Fitur Augmented Reality Berbasis Android (Studi Kasus: Smpn 7 Depok). Jurnal Pinter, 1(1), 76-81. Http:// Journal2. Um. Ac. Id/Index. Php/ Jpb/Article/View/722

Kadek, S. (2010). Pengembangan Mutimedia Untuk Meningkatkan Kualitas Pembelajaran Pada Mata Kuliah Media Pembelajaran. Jurnal Pendidikan Dan Pengajaran, 43(3), 56-58.

Https://Www.Researchgate.Net/Publication/335541585_Evaluasi_Dan_Kriteria_Kualit as_Multimedia_Pembeajaran

Kartini, K. S., \& Putra, I. N. T. A. (2020). Respon Siswa Terhadap Pengembangan Media Pembelajaran Interaktif Berbasis Android. Jurnal Pendidikan Kimia Indonesia, 4(1), 12-19. Https://Doi.Org/10.23887/Jpk.V4i1.24981

Kinasih, S., \& Sinaga, K. (2020). Kajian Penerapan Teori Pembelajaran Bermakna Ausubel Berdasarkan Perspektif Alkitabiah Pada Materi Hidrokarbon [A Study On The Application Of Ausubel's Meaningful Learning Theory On Hydrocarbon Chemical Learning Based On A Biblical Perspective]. Polyglot: Jurnal IImiah, 16(2), 141-153. Https:// Doi. Org /10. 19166/Pji.V16i2.2128

Maesaroh, S., \& \& Malkiah, N. (2015). Media Pembelajaran Interaktif Bahasa Inggris Pengenalan Huruf \& Membaca Berbasis Multimedia Untuk Sekolah Dasar. Jurnal Sisfotek Global, 5(1), 81-86. Https:// Stmikglobal. Ac.Id/ Journal// Ndex. Php /Sisfotek /Article/View/71/73

Mauludin, R., Sukamto, A. S., \& Muhardi, H. (2017). Penerapan Augmented Reality Sebagai Media Pembelajaran Sistem Pencernaan Pada Manusia Dalam Mata Pelajaran Biologi. Jurnal Edukasi Dan Penelitian Informatika (Jepin), 3(2), 117-123. Https:// Doi.Org/ 10.26418/Jp.V3i2.22676

Muhson, A. (2010). Pengembangan Media Pembelajaran Berbasis Teknologi Informasi. Jurnal Pendidikan Akuntansi Indonesia, Viii(2), 1-10. Https:// Journal. Uny. Ac.Id/Index.Php/Jpakun/Article/View/949

Nida, Dewa Made A A, \& Dkk. (2020). Pengembangan Media Kartu Bergambar Berorientasi Pendidikan Karakter Pada Mata Pelajaran Bahasa Bali. Jurnal Edutech Universitas Pendidikan Ganesha., 8(1), 16-31. Https:// Ejournal. Undiksha .Ac. Id/ Index .Php/ Jeu/ Article/View/25393/15846

Nurseto, T. (2011). Membuat Media Pembelajaran Yang Menarik Oleh: Jurnal Ekonomi \& Pendidikan, 8(1), 19-35. Https:// Journal. Uny. Ac. Id/l Ndex. Php/ Jep/Article/View/706

Nusantara, D. B., Irawan, H., \& Si, M. (2012). Perancangan Boardgame Sebagai Media 
Pembelajaran IImu Pengetahuan Alam Untuk Anak Sd Kelas 1. Jurnal Sains Dan Seni Its, 1(1), 22-27. Http://Ejurnal.Its.Ac.Id/Index.Php/Sains_Seni/Article/View/503

Permana, E. P. \&, \& Nourmavita, D. (2017). Pengembangan Multimedia Interaktif Pada Mata Pelajaran Ipa Materi Mendeskripsikan Daur Hidup Hewan Di Lingkungan Sekitar Siswa Kelas Iv Sekolah Dasar. Jurnal Pgsd: Jurnal IImiah Pendidikan Guru Sekolah Dasar, 10(2), 79-85. Https:// Ejournal. Unib.Ac. Id/Index. Php/Pgsd

Prasetyo, S. (2017). Pengembangan Media Pembelajaran Ipa Berbasis Android Untuk Siswa Sd/Mi Sigit. Jmie: Journal Of Madrasah Ibtidaiyah Education, 1(1), 122-141. Http://EJournal.Adpgmiindonesia.Com/Index.Php/Jmie

Rahmi, M. S. M., Budiman, M. A., \& Widyaningrum, A. (2019). Pengembangan Media Pembelajaran Interaktif Macromedia Flash 8 Pada Pembelajaran Tematik Tema Pengalamanku. International Journal Of Elementary Education, 3(2), 178. Https:// Doi. Org/10.23887/ljee.V3i2.18524

Rasyid, Magfirah, D. (2016). Pengembangan Media Pembelajaran Berbasis Multimedia Dalam Konsep Sistem Indera Pada Siswa Kelas Xi Sma. Urnal Pendidikan Biologi, 7(2), 69-80. Http://J Ournal2. Um. Ac. Id// Ndex .Php/ Jpb/ Article/View/722

Rosandi, A. K. F., Tjandrakirana, T., \& Supardi, I. (2016). Pengembangan Multimedia Ipa Berbasis Flash Untuk Meningkatkan Literasi Sains Siswa Smp. Prisma Sains: Jurnal Pengkajian IImu Dan Pembelajaran Matematika Dan Ipa Ikip Mataram, 4(1), 34. Https://Doi.Org/10.33394/J-Ps. V4i1.1138

Sadulloh, U. (2004). Pengantar Filsafat Pendidikan. Alfabeta Bandunh.

Saputra, H. (2016). Peningkatan Daya Serap Siswa Dalam Pembelajaran Matematika Dengan Penerapan Teori Belajar Bermakna David Ausubel. Universitas Jabal Ghafur, 1(1), 21-26. Https:// Jurnal-Lp2m. Umnaw. Ac.ld/ Index.Php/Jp2mipa/Article/Download/71/64

Saputro, Rujianto Eko Dan Saputra, D. I. S. (2015). Pengembangan Media Pembelajaran Mengenal Organ Pencernaan Manusia Menggunakan Teknologi Augmented Reality Rujianto. Jurnal Buana Informatika, 6(2), 153-162. Https://Ojs.Uajy.Ac.Id/Index.Php/Jbi

Sari, Puspita Surya, D. (2013). Pengembangan Multimedia Pembelajaran Interaktif Ipa Dengan Model Pembelajaran Kooperatif Group Investigation Untuk Meningkatkan Kreativitas Pada Siswa Kelas 5 Sdn Purworejo. Innovative Journal Of Curriculum And Educational Technology, 2(2), 30-37. Http://Journal.Unnes.Ac.Id/Sju/Index.Php/Ujet

Setiyaningrum, R. (2013). Pembuatan Media Pembelajaran Ilmu Pengetahuan Alam Untuk Kelas Viii ( Delapan ) Koleksi Hewan Pada Sekolah Menengah Negeri 2 Geyer Kabupaten Grobogan. Seminar Riset Unggulan Nasional Informatika Dan Komputer Fti Unsa 2013, 2(1), 79-84. Http://ljns.Org/Journal/Index.Php/Seruni/Article/View/642

Suadnyana, I. N., Wiyasa, I. K. N., Ardana, I. K., Putra, D. K. N. S., \& Wulandari, I. G. A. A. (2017). Pelatihan Penyusunan Rpp Tematik Integratif Menggunakan Pendekatan Saintifik Bagi Guru-Guru Sekolah Dasar Gugus Viii Abiansemal Badung Tahun Pelajaran 2015/2016. International Journal Of Community Service Learning, 1(1), 6366. Https://Doi.Org/10.23887/ljcsl.V1i1.11908

Sudatha, I. G. W., \& Tegeh, I. M. (2009). Desain Multimedia Pembelajaran I Gde Wawan Sudatha I Made Tegeh Jurusan Teknologi Pendidikan Universitas Pendidikan Ganesha. Jurusan Teknologi Pendidikan Fakultas IImu Pendidikan Universitas Pendidikan Ganesha Singaraja.

Sulistyanto, H., \& Nugroho, A. (2015). Rekayasa Aplikasi Media Pembelajaran Sistem Organ Pada Manusia Berbasis Web. Seminar Nasional Aplikasi Teknologi Informasi (Snati) 
2015, 35-38. Https://Journal.Uii.Ac.Id/Snati/Article/Viewfile/3553/3144

Suprianingsih, Ni Wayan S \& Wulandari, I. G. (2020). Model Problem Posing Berbantuan Media Question Box Berpengaruh Terhadap Kompetensi Pengetahuan Matematika Siswa Sd. Jurnal Mimbar IImu, 25(3), 308-318. Https:// Ejournal. Undiksha. Ac.Id/ Index. Php/Mi/Article/View/25472

Susanto, A. (2013). Teori Belajar Dan Pembelajaran Di Sekolah Dasar. Kencana.

Syahdiani, D. (2015). Pengembangan Multimedia Interaktif Berbasis Inkuiri Pada Materi Sistem Reproduksi Manusia Untuk Meningkatkan Hasil Belajar Dan Melatihkan Keterampilan Berpikir Kritis Siswa. Pendidikan Sains Pascasarjana Universitas Negeri Surabaya, 5(1), 727-741. Https:// Journal. Unesa. Ac.Id/Index.Php/Jpps/Article/View/47

Tamara, M. F., Tulenan, V., Paturusi, S., Elektro, T., Sam, U., \& Manado, J. K. B. (2019). Aplikasi Pembelajaran Interaktif Sistem Pencernaan Manusia Untuk Siswa Sekolah Dasar. Jurnal Teknik Informatika, 14(3), 377-386. Https:// Doi. Org/ 10. 35793/ Jti.14. 3.2019 .27132

Tegeh, D. (2014). Buku Ajar Model Penelitian Pengembangan. Jurusan Teknologi Pendidikan Fakultas IImu Pendidikan Universitas Pendidikan Ganesha.

Udayani, I D A T, D. (1858). Model Creative Problem Solving Terhadap Minat. Jurnal Imiah Pendidikan Dan, 4(2), 284-293. Https:// Ejournal. Undiksha.Ac. Id/Index. Php/Jipp/Article/View/26806

Warsita, B. (2008). Teknologi Pembelajaran Landasan Dan Aplikasinya (1st Ed.). Pt Rineka Cipta.

Yektyastuti, R., \& Ikhsan, J. (2016). Pengembangan Media Pembelajaran Berbasis Android Pada Materi Kelarutan Untuk Meningkatkan Performa Akademik Siswa Sma. Jurnal Inovasi Pendidikan Ipa, 2(1), 88-99. Https://Doi.Org/10.21831/Jipi.V2i1.10289

Yuniasih, Nury, D. (2018). Pengembangan Media Interaktif Berbasis Ispring Materi Sistem Pencernaan Manusia Kelas V Di Sdn Ciptomulyo 3 Kota Malang. Jip, 8(2), 85-94. Http://Ejournal.Unikama.Ac.Id/Index.Php/Jrnspirasi/Article/View/2647 